\title{
Effects on facial dysfunction and swallowing capacity of intraoral stimulation early and late after stroke
}

\author{
Mary K.D. Hägg ${ }^{\mathrm{a}, \mathrm{b}, *}$ and Lita I.E. Tibbling ${ }^{\mathrm{c}}$ \\ ${ }^{a}$ Speech \& Swallowing Centre, Department of Otorhinolaryngology, Hudiksvall Hospital, Sweden \\ ${ }^{\mathrm{b}}$ Centre for Research \& Development, Uppsala University/County Council of Gävleborg, Gävle, Sweden \\ ${ }^{c}$ Department of Otorhinolaryngology, Linköping University, Linköping, Sweden
}

\begin{abstract}
.
BACKGROUND: Most patients with post-stroke dysphagia are also affected by facial dysfunction in all four facial quadrants. Intraoral stimulation can successfully treat post-stroke dysphagia, but its effect on post-stroke facial dysfunction remains unknown. OBJECTIVE: This study aimed to investigate whether intraoral stimulation after stroke has simultaneous effects on facial dysfunction in the contralateral lower facial quadrant and in the other three facial quadrants, on lip force, and on dysphagia.

METHODS: Thirty-one stroke patients were treated with intraoral stimulation and assessed with a facial activity test, lip force test, and swallowing capacity test at three time-points: before treatment, at the end of treatment, and at late follow-up (over one year after the end of treatment).

RESULTS: Facial activity, lip force, and swallowing capacity scores were all improved between baseline and the end of treatment $(P<0.001$ for each), with these improvements remaining at late follow-up. Baseline and treatment data did not significantly differ between patients treated short and late after stroke.

CONCLUSIONS: Treatment with intraoral stimulation significantly improved post-stroke dysfunction in all four facial quadrants, swallowing capacity, and lip force even in cases of long-standing post-stroke dysfunction. Furthermore, such improvement remained for over one year after the end of treatment.
\end{abstract}

Keywords: Facial dysfunction, dysphagia, lip force, stroke, oral screen, palatal plate

\section{Introduction}

Following a stroke, most patients exhibit oropharyngeal dysphagia, as well as decreased function not only in the lower facial quadrant contralateral to the cortical lesion but in all four facial quadrants supplied by the facial nerves (Hägg \& Tibbling, 2014; Yildiz et al., 2005). Stroke-related dysphagia is improved by intraoral sensory and motor stimulation (Hägg \& Larsson,

*Address for correspondence: Mary Hägg, DDS, Ph.D, Speech \& Swallowing Centre, Department of Otorhinolaryngology, Hudiksvall Hospital, SE 82481 Hudiksvall, Sweden. Tel.: +46 650 92754; Fax: +46 650 92412; E-mail: mary.hagg@lg.se.
2004), but it remains unknown to what extent intraoral stimulation can also improve the stroke-related dysfunction in all four facial quadrants.

The present study aimed to investigate whether intraoral stimulation early and late after a first-ever stroke attack would simultaneous affect dysphagia, lip force, and facial dysfunction in the contralateral lower facial quadrant as well as in the other three facial quadrants. To this end, patients with dysphagia after a stroke attack were examined with a facial activity test (FAT) (Hägg \& Larsson, 2004), a lip force test (LF) (Hägg, Olgarsson, \& Anniko, 2008), and a swallowing capacity test (SCT) (Kalyanee, Nathadwarawala, McGroary, \& 
Wiles, 1994; Nathadwarawala, Nicklin, \& Wiles, 1992) at baseline before treatment with intraoral stimulation, at the end of treatment, and at follow-up.

\section{Methods}

\subsection{Study design}

We designed a prospective clinical study of the effects of intra-oral stimulation short and late after a first-ever stroke attack, regarding dysphagia, lip force, and facial dysfunction in the contralateral lower facial quadrant and in the other three facial quadrants. A facial dysfunction was defined as the inability to properly perform facial and periorbital muscle activities on demand in any of the four facial quadrants. This study was designed according to good clinical practice (GCP). All data were collected according to an initial protocol.

\subsection{Study population}

The initial patient cohort comprised 38 patients who were consecutively referred from a neurological department to a Speech and Swallowing Centre because they exhibited subjective oropharyngeal dysphagia following a first-ever stroke attack. The included patients did not have any neurological disease other than stroke. Seven of these 38 patients were excluded: 6 due to a new stroke, and 1 due to inability to cooperate. The final study comprised 31 patients (11 women and 20 men) who participated during the years 2006 to 2012 . Written or verbal consent to take part in the study was obtained from all participants, and the study was approved by the local Ethics Committee for Human Research at the Uppsala Medical Faculty, Sweden (Dnr 2004: M-435).

The 31 included patients were divided into two groups. Group 1 comprised 11 patients (median age, 71 years; range, 59-81 years) whose study involvement began within 5 weeks after their stroke attack. Group 2 comprised 20 patients (median age, 61 years; range, 46-82 years) whose study involvement began at a median of 57 weeks (range, 6 weeks- 8.8 years) after their stroke attack. The two groups were investigated with a facial activity test (FAT), a swallowing capacity test (SCT), and a lip force test (LF) at three different occasions: at baseline before the start of intraoral stimulation, after a three-month period of treatment with intraoral stimulation, and at follow-up at least one year after the end of treatment. One patient in Group 2 was missing at follow-up. Patient compliance was monitored at the clinic three times during the 3-month treatment period.

\subsection{Facial activity test}

A facial activity test (FAT) (Hägg \& Larsson, 2004) including seven different exercises, each scored on a five-point scale, was used to measure the motor function of all four facial quadrants. The patients were seated in an upright and slightly forward position, and instructed to perform a series of movements for the upper facial branch (close the eyes, raise the eyebrows, and wrinkle the eyebrows) and for the lower facial branch (wrinkle the nose, pout the lips, smile, and repeat "oh-eeh" three times as quickly as possible). The score sum for each facial quadrant was divided by the number of items tested. A score sum of zero = normal, $1=$ mild dysfunction, $2=$ moderate dysfunction, $3=$ severe dysfunction, and $4=$ total inability. The intra/inter-rater reliability of scoring orofacial muscle function reportedly has a high kappa coefficient of 0.90 (Hägg \& Larsson, 2004).

\subsection{Swallowing capacity test}

When wrong-way swallowing was suspected, the patient was initially given a teaspoon of water one to three times. When the patient was unable to swallow anything at all or had an initial wrong-way swallowing, the SC was graded as zero. In other cases, the patient was instructed to sit upright and swallow $150 \mathrm{ml}$ of water as quickly as possible without pausing. The time was recorded from onset of drinking until completion of the final swallow. The remaining water in the glass was measured. Swallowing capacity (SC) was defined as the amount of water swallowed divided by time, expressed as millilitres per second $(\mathrm{ml} / \mathrm{s})$. A SC of $10 \mathrm{ml} / \mathrm{s}$ is regarded as the lower normal limit (Kalyanee, Nathadwarawala, McGroary, \& Wiles, 1994; Nathadwarawala, Nicklin, \& Wiles, 1992). The SCT has a high intra/inter-rater and test-retest reliability, and is reportedly a reliable and valid index for assessing SC in neurological patients with disordered swallowing, and of value in monitoring therapeutic response (Kalyanee, Nathadwarawala, McGroary, \& Wiles, 1994; Nathadwarawala, Nicklin, \& Wiles, 1992).

\subsection{Lip force}

Lip force (LF) was recorded with an LF100 (MHC1 AB Detector, Gothenburg, Sweden), which is a modified strain gauge connected to a predentally placed 
preformed acrylic oral screen (Hägg, Olgarsson, \& Anniko, 2008) for recording the ability of lips to withstand a pulling pressure. The detector is connected to an electronic unit for measuring maximum LF in newtons $(\mathrm{N})$. The subject was instructed to hold the screen for as long as possible while trying to maximally resist the pulling force by tightening the lips. Pulling was applied at right angles to the patient's lips, with increasing force for up to $10 \mathrm{~s}$, or until the subject lost grip of the oral screen. The maximum LF value was recorded by an independent person, and the investigator was blinded to data. The lower normal LF limit is $15 \mathrm{~N}$ (Hägg, Olgarsson, \& Anniko, 2008).

\subsection{Intraoral stimulation therapy}

All 31 patients received 3 months of intraoral stimulation self-training therapy with either an oral screen (Hägg \& Anniko, 2008) $(n=18)$ or a palatal plate (Hägg \& Tibbling, 2013; Hägg \& Larsson, 2004) $(n=13)$. The oral screen was predentally placed behind closed lips. The patient was instructed to withhold the screen against a pulling force for at least 5 seconds, repeated three times, and to perform this sequence three times each day. The palatal plate was inserted in the upper jaw, and the patient was instructed to repeatedly perform 9 different exercises over 10-30 minutes, 3 times per day (Hägg \& Tibbling, 2013; Hägg \& Larsson, 2004).

\subsection{Statistics}

From the outset, professional statisticians and a data manager from Uppsala Clinical Research Centre (UCR) were involved in planning the study design. The Good Clinical Practice (GCP) database consolidated all study data and all analyses, which were performed according to the initial protocol. Wilcoxon's signed rank test was used for within-group comparisons. Differences between Group 1 and Group 2 were evaluated with the Mann-Whitney U test. A $P$ value of $<0.05$ was regarded as significant. All statistical analyses were performed using SAS version 9.1 software (SAS Institute Inc., Carey, NC, USA).

\section{Results}

At baseline, all 31 patients had facial dysfunction in the lower quadrant contralateral to the cortical lesion (CLFQ), 52\% had a pathological FAT score in all four facial quadrants, and $93 \%$ of patients exhibited dysfunction in some of the other three facial quadrants
(Q3). At the end of treatment, 31\% patients had normal CLFQ function (27\% in Group 1 and 35\% in Group 2 ), and 12 patients had normal Q3 function (36\% in Group 1 and $40 \%$ in Group 2). FAT scores significantly improved after the treatment period, and these improvements remained at follow-up at least one year after the end of treatment, Tables 1 and 2. Figure 1 shows the improvement of CLFQ activity after treatment and at late follow-up. LF and SCT scores were also significantly improved at the end of treatment and these improvements were also still observed at late followup, Tables 3 and 4. A normal SCT score was found in $7 \%$ of patients at baseline, $42 \%$ at the end of treatment, and $43 \%$ at follow-up (respectively, $0 \%, 46 \%$, and $46 \%$ in Group 1 and 10\%, 40\%, and 40\% in Group 2). Groups 1 and 2 did not significantly differ in any of the tested variables (FAT, SCT, and LF) at any of the test occasions.

\section{Discussion}

Our present results showed that intraoral sensory and motor stimulation significantly improved dysfunction in the four facial quadrants as assessed by FAT (Hägg \& Larsson, 2004), and dysphagia as assessed by SCT (Kalyanee, Nathadwarawala, McGroary, \& Wiles, 1994; Nathadwarawala, Nicklin, \& Wiles, 1992), among patients after a first-ever stroke attack. The baseline data and treatment data did not differ between the two groups with long and short intervals between stroke and start of treatment, and thus it is unlikely that the treatment effects on facial dysfunction and dysphagia were due to spontaneous remission.

The lip force test (LF) (Hägg, Olgarsson, \& Anniko, 2008) used in this study assesses the facial nerve ability to activate lip muscles, as well as the muscular strength, which was shown to be significantly increased by both intraoral stimulation modalities applied in the present study. In contrast to the facial muscles in the lower quadrants, those in the upper facial quadrants are not directly trained with intraoral stimulation. This raises the question of how facial muscle dysfunction can be improved without active training of the involved muscle. The utilized intraoral stimulation techniques stimulate a number of cranial sensory and motor nerves, including the facial nerves that supply the lips, the stylohyoideus muscle, the posterior digastric muscle, the buccal muscle, the constrictor pharyngeal superior muscle, and the levator veli palatini muscle (together with the vagal nerve). It seems reasonable that activation of 
Table 1

Facial activity test (FAT) scores for the lower quadrant contralateral to the cortical lesion (CLFQ) before and after intraoral stimulation

\begin{tabular}{|c|c|c|c|c|c|c|c|}
\hline $\begin{array}{l}\text { FAT, CLFQ } \\
\text { different } \\
\text { occasions }\end{array}$ & $\begin{array}{c}\text { Total group } \\
\text { M (range) } \\
n=31\end{array}$ & & $\begin{array}{c}\text { Group 1 } \\
\text { M (range) } \\
n=11\end{array}$ & & $\begin{array}{c}\text { Group 2 } \\
\text { M (range) } \\
n=20\end{array}$ & & \\
\hline Baseline & $2.0(1.5$ to 3.0$)$ & & $1.8(1.5$ to 3.5$)$ & & $2.3(1.0$ to 3.0$)$ & & \\
\hline End of treatment & $0.8(0.5$ to 1.5$)$ & & $0.8(0.3$ to 2.5$)$ & & $0.8(0.5$ to 1.5$)$ & & \\
\hline Follow-up & $0.4(0.3$ to 1.0$)$ & & $0.5(0.3$ to 2.0$)$ & & $0.3(0.0$ to 1.3$)$ & & \\
\hline $\begin{array}{l}\text { FAT, CLFQ Changes } \\
\text { between different } \\
\text { occasions }\end{array}$ & $\mathrm{M}(95 \% \mathrm{CI})$ & $\begin{array}{c}\text { Total } \\
\text { group } \\
P \text { value }\end{array}$ & $\mathrm{M}(95 \% \mathrm{CI})$ & $\begin{array}{l}\text { Group } 1 \\
P \text { value }\end{array}$ & $\mathrm{M}(95 \% \mathrm{CI})$ & $\begin{array}{l}\text { Group } 2 \\
P \text { value }\end{array}$ & $\begin{array}{c}\text { Difference } \\
\text { between Group } 1 \\
\text { and Group } 2 P \text { value }\end{array}$ \\
\hline Baseline-End of treatment & $-1.0(-1.3$ to -0.8$)$ & $<0.001$ & $-1.0(-1.5$ to -0.5$)$ & $<0.001$ & $-0.8(-1.3$ to -0.3$)$ & $<0.001$ & 0.417 \\
\hline Baseline-Follow-up & $-1.3(-1.8$ to -0.8$)$ & $<0.001$ & $-1.5(-1.8$ to -0.8$)$ & $<0.001$ & $-1.0(-1.8$ to -0.3$)$ & $<0.001$ & 0.242 \\
\hline End of treatment-Follow-up & $-0.3(-0.5$ to 0.0$)$ & 0.035 & $-0.3(-0.8$ to 0.0$)$ & 0.117 & $-0.3(-0.5$ to 0.0$)$ & 0.163 & 0.566 \\
\hline
\end{tabular}

$\mathrm{M}=$ median value; $\mathrm{CI}=$ confidence interval. $P$ values within the Total group, Group 1, and Group 2 determined with the Wilcoxon's signed rank test. $P$ values between Group 1 and Group 2 determined with the Mann Whitney U-test.

Table 2

Facial activity test (FAT) scores in three facial quadrants (3Q), not including the lower quadrant contralateral to the cortical lesion, before and after intraoral stimulation

\begin{tabular}{|c|c|c|c|c|c|c|c|}
\hline $\begin{array}{l}\text { FAT, 3Q On } \\
\text { different } \\
\text { occasions }\end{array}$ & $\begin{array}{c}\text { Total group } \\
\mathrm{M} \text { (range) } \\
n=31\end{array}$ & & $\begin{array}{c}\text { Group } 1 \\
\text { M (range) } \\
n=11\end{array}$ & & $\begin{array}{c}\text { Group } 2 \\
\text { M (range) } \\
n=20\end{array}$ & & \\
\hline $\begin{array}{l}\text { Baseline } \\
\text { End of treatment } \\
\text { Follow-up }\end{array}$ & $\begin{array}{l}1.1(0.3 \text { to } 2.1) \\
0.2(0.1 \text { to } 0.7) \\
0.1(0.0 \text { to } 0.3)\end{array}$ & & $\begin{array}{l}1.1(0.3 \text { to } 3.3) \\
0.2(0.1 \text { to } 2.5) \\
0.1(0.0 \text { to } 1.1)\end{array}$ & & $\begin{array}{l}1.1(0.3 \text { to } 2.1) \\
0.2(0.1 \text { to } 1.0) \\
0.1(0.0 \text { to } 0.5)\end{array}$ & & \\
\hline $\begin{array}{l}\text { FAT, 3Q Changes } \\
\text { between different } \\
\text { occasions }\end{array}$ & $\mathrm{M}(95 \% \mathrm{CI})$ & $\begin{array}{c}\text { Total } \\
\text { group } \\
P \text { value }\end{array}$ & $\mathrm{M}(95 \% \mathrm{CI})$ & $\begin{array}{l}\text { Group } 1 \\
P \text { value }\end{array}$ & $\mathrm{M}(95 \% \mathrm{CI})$ & $\begin{array}{l}\text { Group } 2 \\
P \text { value }\end{array}$ & $\begin{array}{c}\text { Difference } \\
\text { between Group } 1 \\
\text { and Group } 2 P \text { value }\end{array}$ \\
\hline Baseline-End of treatment & $-0.4(-1.0$ to -0.2$)$ & $<0.001$ & $-0.4(-1.0$ to -0.2$)$ & $<0.001$ & $-0.4(-1.2$ to -0.1$)$ & $<0.001$ & 0.604 \\
\hline Baseline-Follow-up & $-0.4(-1.1$ to -0.2$)$ & $<0.001$ & $-0.4(-1.8$ to -0.2$)$ & $<0.001$ & $-0.4(-1.1$ to -0.1$)$ & $<0.001$ & 0.504 \\
\hline End of treatment-Follow-up & $-0.0(-0.2$ to 0.0$)$ & 0.002 & $0.0(-0.2$ to 0.0$)$ & 0.125 & $-0.1(-0.2$ to 0.0$)$ & 0.012 & 0.588 \\
\hline
\end{tabular}

$\mathrm{M}=$ median value; $\mathrm{CI}=$ confidence interval. $P$ values within the Total group, Group 1, and Group 2 determined with the Wilcoxon's signed rank test. $P$ values between Group 1 and Group 2 determined with the Mann Whitney U-test.

the muscles in the two upper facial quadrants could be regulated through an orofacial projection system in the cortex.

There are precedents for such regulation, as functional linkage has been demonstrated between the orbicularis oculi and the orbicularis oris by several authors (e.g. Ertekin, Eryasar, Gürgör, Arici, Secil, \& Kurt, 2013). Additionally, Morecraft, StilwellMorecraft, and Rossing (2004) reported clinical observations that indicate a higher oral regulation of facial expression - both voluntary and emotional that does not occupy a specific site in the brain or manifest through a single neural projection system. Mahadevappa, Vora, Graham, and Nesathurai (2010) demonstrated that bilateral cortical signals from the upper and lower facial quadrants are projected to both facial nuclei in the brain stem. Consequently, the facial expression muscles in the upper facial quadrants can be activated through connections in the cortex other than those affected by a stroke attack.
The present results also showed simultaneous improvements in swallowing capacity and facial motor function at the end of treatment, which further suggest a common regulation system for orofacial and swallowing function. Ertekin, Eryasar, Gürgör, Arici, Secil, and Kurt (2013) reported that the orbicularis oris and the orbicularis oculi were intermittently synchronized with swallowing. They proposed that some reflexes, like those related to swallowing, originate partly from the intraoral trigeminal afferents. The palatal plate and the oral screen used in our study can trigger the sensory part of the trigeminal nerve, which could thus be related to the observed improvements in function.

\section{Conclusion}

Treatment with intraoral stimulation can significantly improve post-stroke dysfunction in all four facial quadrants, swallowing capacity, and lip force even in 


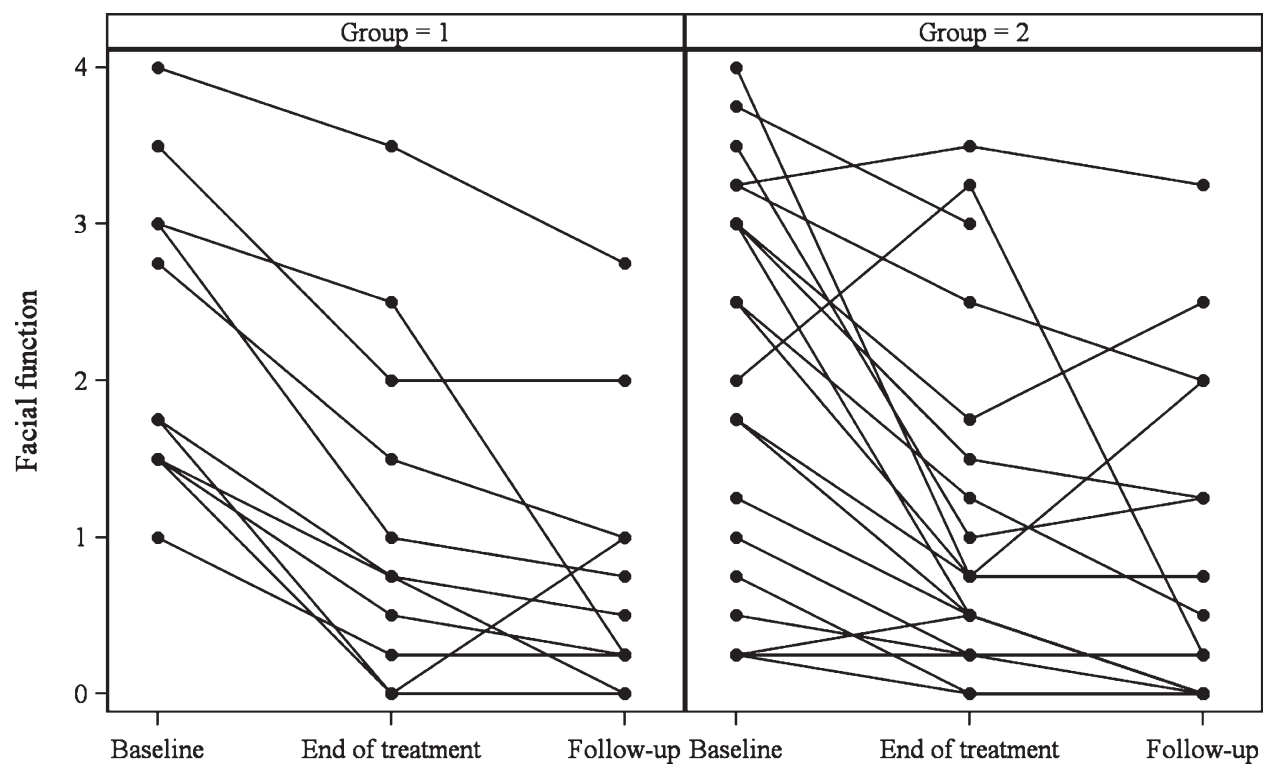

Fig. 1. Outcome of orofacial stimulation treatment regarding dysfunction in the lower facial quadrant contralateral to the cortical lesion. In Group $1(n=11)$, baseline assessment was within 5 weeks after stroke. In Group $2(n=20)$, baseline assessment occurred a median of $1 \frac{1 / 2}{2}$ years after stroke. Facial function was measured by facial activity test (FAT) score (range, $0-4$ ).

Table 3

Swallowing capacity test (SCT) scores (in $\mathrm{ml} / \mathrm{sec}$ ) before and after intraoral stimulation

\begin{tabular}{|c|c|c|c|c|c|c|c|}
\hline $\begin{array}{l}\text { SCT On } \\
\text { different } \\
\text { occasions }\end{array}$ & $\begin{array}{c}\text { Total group } \\
\mathrm{M} \text { (range) } \\
n=31\end{array}$ & & $\begin{array}{c}\text { Group 1 } \\
\text { M (range) } \\
n=11\end{array}$ & & $\begin{array}{c}\text { Group 2 } \\
\text { M (range) } \\
n=20\end{array}$ & & \\
\hline Baseline & $0.5(0.0$ to 2.8$)$ & & $0.0(0.0$ to 3.4$)$ & & $1.1(0.0$ to 4.8$)$ & & \\
\hline End of treatment & $6.5(4.0$ to 12.1$)$ & & $7.4(4.9$ to 13.6$)$ & & $6.2(1.7$ to 13.3$)$ & & \\
\hline Follow-up & $7.6(7.0$ to 11.5$)$ & & $9.7(6.1$ to 12.1$)$ & & $7.3(6.6$ to 18.3$)$ & & \\
\hline $\begin{array}{l}\text { SCT Changes } \\
\text { between different } \\
\text { occasions }\end{array}$ & $\mathrm{M}(95 \% \mathrm{CI})$ & $\begin{array}{c}\text { Total } \\
\text { group } \\
P \text { value } \\
\end{array}$ & $\mathrm{M}(95 \% \mathrm{CI})$ & $\begin{array}{l}\text { Group } 1 \\
P \text { value }\end{array}$ & $\mathrm{M}(95 \% \mathrm{CI})$ & $\begin{array}{l}\text { Group } 2 \\
P \text { value }\end{array}$ & $\begin{array}{l}\text { Group 1- } \\
\text { Group } 2 \\
P \text { value }\end{array}$ \\
\hline Baseline-End of treatment & $4.4(3.0$ to 6.5$)$ & $<0.001$ & $6.5(3.1$ to 12.0$)$ & $<0.001$ & $3.9(1.1$ to 5.7$)$ & $<0.001$ & 0.142 \\
\hline Baseline-Follow-up & $7.1(5.1$ to 9.7$)$ & $<0.001$ & $7.3(5.1$ to 12.1$)$ & $<0.001$ & $7.0(3.9$ to 14.7$)$ & $<0.001$ & 0.775 \\
\hline End of treatment-Follow-up & $2.0(0.2$ to 3.9$)$ & 0.005 & $1.9(-2.4$ to 4.7$)$ & 0.520 & $3.5(0.2$ to 7.0$)$ & 0.008 & 0.216 \\
\hline
\end{tabular}

$\mathrm{M}=$ median value; $\mathrm{CI}=$ confidence interval. $P$ values within the Total group, Group 1, and Group 2 determined with the Wilcoxon's signed rank test. $P$ values between Group 1 and Group 2 determined with the Mann Whitney U-test.

Table 4

Lip force $(\mathrm{LF})$ in newton $(\mathrm{N})$ before and after intraoral stimulation

\begin{tabular}{|c|c|c|c|c|c|c|c|}
\hline $\begin{array}{l}\text { LF On different } \\
\text { occasions }\end{array}$ & $\begin{array}{c}\text { Total group } \\
\mathrm{M} \text { (range) } \\
n=14\end{array}$ & & $\begin{array}{c}\text { Group } 1 \\
\text { M (range) } \\
n=7\end{array}$ & & $\begin{array}{c}\text { Group } 2 \\
\text { M (range) } \\
n=7\end{array}$ & & \\
\hline Baseline & $10.5(3.0$ to 24.0$)$ & & $13.0(0.0$ to 27.0$)$ & & $8.0(0.0$ to 26.0$)$ & & \\
\hline End of treatment & $23.0(10.0$ to 29.0$)$ & & $22.0(7.0$ to 44.0$)$ & & $24.0(0.0$ to 36.0$)$ & & \\
\hline Follow-up & $23.0(16.0$ to 30.0$)$ & & $22.0(11.0$ to 30.0$)$ & & $23.5(9.0$ to 42.0$)$ & & \\
\hline LF Changes between different occasions & $\mathrm{M}(95 \% \mathrm{CI})$ & $\begin{array}{c}\text { Total } \\
\text { group } \\
P \text { value } \\
\end{array}$ & $\mathrm{M}(95 \% \mathrm{CI})$ & $\begin{array}{l}\text { Group } 1 \\
P \text { value }\end{array}$ & $\mathrm{M}(95 \% \mathrm{CI})$ & $\begin{array}{l}\text { Group } 2 \\
P \text { value }\end{array}$ & $\begin{array}{c}\text { Group } 1- \\
\text { Group } 2 \\
P \text { value } \\
\end{array}$ \\
\hline Baseline-End of treatment & $7.0(2.0$ to 17.0$)$ & $<0.001$ & $7.0(1.0$ to 22.0$)$ & 0.016 & $2.0(0.0$ to 18.0$)$ & 0.063 & 0.412 \\
\hline Baseline-Follow-up & $13.0(3.0$ to 16.0$)$ & $<0.001$ & $8.0(1.0$ to 16.0$)$ & 0.016 & 15.0 (0.0 to 24.0$)$ & 0.063 & 0.342 \\
\hline End of treatment-Follow-up & $0.0(-4.0$ to 6.0$)$ & 0.576 & $-1.0(-14.0$ to 8.0$)$ & 0.625 & $3.0(0.0$ to 13.0$)$ & 0.125 & 0.108 \\
\hline
\end{tabular}

$\mathrm{M}=$ median value; $\mathrm{CI}=$ confidence interval. $P$ values within the Total group, Group 1 , and Group 2 determined with the Wilcoxon's signed rank test. $P$ values between Group 1 and Group 2 determined with the Mann Whitney U-test. 
cases of long-standing dysfunction after a stroke attack. Furthermore, such improvement will remain for over one year after the end of treatment.

\section{Acknowledgments}

This work was supported by grants from the Center for Research and Development, Uppsala University; the Gävleborg County Council, Sweden; and the Council for Regional Research in The Uppsala and Örebro region, Sweden. Biostatitician Lisa Wernroth and clinical data manager Manuela Zanfir, Uppsala Clinical Research Center (UCR) were involved in transmitting data to the database.

\section{Authors' contributions}

Authorship credit for Mary Hägg is based on substantial contributions to study conception and design, data acquisition, patient investigations, administration and supervision, data analyses and interpretation, and paper writing. Authorship credit for Lita Tibbling is based on substantial contributions to study conception and design, data analyses and interpretation, paper writing, and paper revision that were critical for important intellectual content.

\section{Declaration of interest}

The authors declare that there are no conflicts of interest or funding regarding publication of this paper.

\section{References}

Ertekin, C., Eryasar, G., Gürgör, N., Arici, S., Secil, Y., \& Kurt, T. (2013). Orbicularis oculi muscle activation during swallowing in humans. Experimental Brain Research, 224, 79-91.

Hägg, M., \& Tibbling, L. (2014) Four-quadrant facial function in dysphagic patients after stroke and in healthy controls. Neurology Research International, Volume 2014, Article ID 672685, 5 pages, http://dx.doi.org/10.1155/2014/672685

Hägg, M., \& Tibbling, L. (2013). Longstanding effect and outcome differences of palatal plate and oral screen training on strokerelated dysphagia. The Open Rehabilitation Journal, 6, 26-33.

Hägg, M., Olgarsson, M., \& Anniko, M. (2008). Reliable lip force measurement in healthy controls and in patients with stroke: A methodological study. Dysphagia, 2, 291-296.

Hägg, M., \& Anniko, M. (2008). Lip muscle training in stroke patients with dysphagia. Acta Otolaryngologica, 128, 1027-1033.

Hägg, M., \& Larsson, B. (2004). Effects of motor and sensory stimulation in stroke patients with longlasting dysphagia. Dysphagia, 19, 219-230.

Kalyanee, M., Nathadwarawala, K. M., McGroary, A., \& Wiles, C. M. (1994). Swallowing in neurological outpatients: Use of a timed test. Dysphagia, 9, 120-129.

Mahadevappa, K., Vora, A., Graham, A., \& Nesathurai, S. (2010). Facial paralysis: A critical review of accepted explanations. Medical Hypothesis, 74, 508-509.

Morecraft, R. J., Stilwell-Morecraft, K. S., \& Rossing, W. R. (2004). The motor cortex and facial expression: New insights from neuroscience. The Neurologist, 10, 235-249.

Nathadwarawala, K. M., Nicklin, J., \& Wiles, C. M. (1992). A timed test of swallowing capacity for neurological patients. Journal Neurology Neurosurgery and Psychiatry, 55, 822-825.

Yildiz, N., Ertekin, C., Ozdemirkiran, T., Yildiz, S. K., Aydogdu, I., Uludag, B., \& Secil, Y. (2005). Corticonuclear innervation to facial muscles in normal controls and in patients with central facial paresis. Journal Neurology, 252, 429-435. 